\title{
Real Time Data Capture: A Response to Unsustainable Dumping of Disposable Diapers and Sanitary Pads in Gweru City, Zimbabwe
}

\author{
Victor Kufa Nyamayedenga ${ }^{*}$ and Prof. Maria. Tsvere, PhD \\ Institute of Lifelong Learning and Development Studies, Centre for Development Studies \\ Chinhoyi University of Technology, Zimbabwe \\ "Corresponding author: maria.tsvere@gmail.com
}

\begin{abstract}
The sustainable management of used disposable diapers and sanitary pads (Absorbent Hygienic Products) is undoubtedly a topical issue in municipalities across the developing world. This article is based on a bigger study which investigated how the city of Gweru can best manage this waste using a model that adjusts itself in response to real time data. Purposive and cluster sampling were employed to select the wards and the respondents respectively. Data was gathered using both qualitative and quantitative techniques. Particularly, semi-structured questionnaires were augmented by observations and in-depth interviews of key informants. The study found out that the municipality in Gweru was fighting a problem they had not yet measured; hence they were acting on vague data. Results of this study are likely to stimulate further research on how real time data on waste can be gathered. The results are also likely to shape the future of waste management in cities across the developing world. The main contribution of this study to the existing body of literature is its recommendation on the usage of real time data to drive waste management.
\end{abstract}

Key words: Disposable diapers, sanitary pads, absorbent hygienic products (AHPs), waste management, real time data, Gweru

\section{Introduction}

The primary aim of this study was to craft a data driven, self-adjusting waste management model that can be applied by the Gweru City Council in its quest to fight the scourge of illegal dumping of disposable diapers and sanitary pads. This article attempts to show the feasibility of a data inspired waste management model. According to Macmillan Education (2007), real time, refers to the actual time something occurs. So real time data refers to information that is made use of as soon as it is received mainly via online platforms. According to Wambui, Muchiri, and Makindi (2015), many local authorities in the developing world lack the adequate means to handle and dispose waste in an environmental friendly manner hence the cities are grappling with the management of used disposable diapers and menstrual pads, often referred to as absorbent hygienic products (AHPs). Whereas it is common to see these AHPs thrown away at undesignated places, the practice has created unsightly images in towns, especially in the developing world.

On a global scale, a number of studies have shown that methods of disposal are determined by among other factors, the level of development of a country or a town. Landfilling and thermal treatment of waste are the most common methods of municipal solid waste disposal in high income countries while the poor or middle income countries tend to dispose their waste in open dumps (Bhada-Tata \& Hoornweg, 2012). Developed countries which seem to be far advanced in the use of the ISWM system do not have the nagging problem of illegal dumping of AHPs. Developing countries, however, were cited by (Memon, 2010) as lagging behind in terms of 
adopting the ISWM system. The author mentions that traditionally, many cities in the developing countries did not have a dedicated waste management plan and waste management was down on the priority list for most of the local and national governments. This was probably the reason why there are numerous illegal dumps, especially those of AHPs.

Continentally, disposable diapers and sanitary pads continue to be a big problem. A big number of these AHPs are being dumped in the neighbourhoods due to poor or non-existent waste management systems (Elledge, Muralidharan, Woodward, Parker, Ravndal, Siddiqui and Toolaram, 2018). Some of the AHPs are dumped at municipal dumps (Kamba, 2018) while some suffer any one of many other small ways of dealing with the AHPs e.g. burying or burning them. Of all these methods, the most ideal seems to be the one where the diapers and pads are dumped at the municipal dumps. It is important to state that while this might be the ideal disposal method, in the African context, it still has serious problems of its own, since it does not offer conditions that are ideal for diaper decomposition (The Manica Post, 2016). The AHPs that find their way to the municipal dumps, therefore, continue to pose a serious threat to the environment mainly because of the fact that the dumps that are not lined the way landfills are supposed to be lined. That being the case, it means ground water is in great danger of being polluted by way of the leachate that is given off by the waste. So it can be concluded that the disposal of AHPs on the African continent is still wholesomely very flawed. If these challenges are to be addressed, any solution that is proposed should comprehensively review how the diaper is handled from the moment it leaves the shop right up to the time it gets to the municipal dump.

On a local scale, Matiashe (2018)'s News Day article reported that Zimbabwe imported diapers worth about $\$ 7.5$ million. With such staggering figures, there is no doubt that disposable diapers and their sister products, the sanitary pads, can potentially pose some serious environmental challenges. While the convenience of these disposable diapers and pads is unquestionable, many users of these AHPs bemoan the poor collection of refuse bins which leaves many with no option at all except to dump, bury or burn the used diapers (Matiashe, 2018). All the disposal ways discussed here basically sum up the ways the majority of women in Zimbabwe's urban high density suburbs dispose diaper waste.
This discussion leaves no doubt at all that the majority, if not all the methods that are used are very much in conflict with the integrated solid waste management system.

Previous research seems to go in circles, around the same recommendations. One of the most prominent recommendations is the fact that local authorities must acquire enough materials for waste management. Consistent with this trend, Mathe (2015) proposes that governments should ensure that there are no material shortages in the waste management sector. Diaz (2011) bemoaned the fact that there is a disconnection between the waste management plans and the material resources needed for the work. Mafume, Zendera, Mutetwa and Musimbo (2016) recommended that refuse workers should be increased to optimum levels. Adogu (2015) recommended the serious adoption of reuse, recycling, recovery, composting and incineration processes. Tembo and Chazireni (2016) recommended that local authorities should put in place waste management plans that include all stakeholders. Nyanzou and Jerie (2014) uniquely proposed the crafting of waste management models that are tailor made to suit each constituency according to its needs. Another unique proposition by Wilson, Whiteman and Tormin (2001) was that of privatising the waste management services so as to bring about an improvement in service delivery. Mangizvo (2014) came out strongly in support of a return to reusable diapers by introducing subsidies that promote use of reusable diapers and introduction of taxes that discourage the use of disposable diapers.

These studies did not focus on real time data concerning the AHPs, for example, how many diapers are dumped in an area? There is a glaring lack of research solutions that are inspired by real time data. As a way of addressing this gap, this study sought to find a solution that is inspired by real time data. In line with this objective, Wilson, Whiteman and Tormin (2001) say that 'if you don't measure it, you can't manage it.' This study was done in the high density areas of Gweru city because these areas are at the epicentre of illegal disposal of AHPs.

Against this backdrop, the purpose of this study was to design a model that had a unique Gweru signature. In other words, while all the recommendations mentioned in the previous paragraph can be adopted, this article focuses on 
the bigger study's aim to design a model which would be influenced by the character of Gweru City. So this article is specifically driven by one primary objective: to develop a home grown framework to solve the problem of unsustainable disposal of AHPs, in response to the social, economic and political situation in the city.

\section{Research Methodology}

This section presents the methodology that guided this study.

\section{Research Design}

In line with the pragmatic philosophy, this study rightly applied the mixed method approach. It employed both qualitative and quantitative data collection techniques. The descriptive survey employed semi structured questionnaires whose responses were augmented by observation and indepth interviews of key informants. The study being descriptive in nature, the descriptive approach was employed because it was important to observe the research subjects without influencing them in any way.

\section{Study Area}

Gweru town lies at the heart of the Midlands Province in Zimbabwe. It is the provincial capital city. According to the latest census figures (Zimbabwe National Statistics Agency, 2012), Gweru urban has a female population of 84361 , a male population of 73,504 to give a total of 157865 people. The majority of these people reside in the high density areas of Mtapa, Mambo, Ascot, Senga, Nehosho and Mkoba. The study focused on the population of wards 5 to 17 . The total population in these 12 wards, according to Zimbabwe National Statistics Agency (2012) was noted to be 121,036 . Of these 64,691 were female and 56,345 were male. The majority of the people in these areas are selfemployed in the informal sector. The total number of households in this study population was 31562. For the purpose of this study, the number of households was given pre-eminence ahead of the total population of these areas.

\section{Data Gathering Procedure}

Permission to conduct this study was sought from the local authorities. Following the granting of the permission, a test run of the questionnaire was done to clear all weaknesses that could be inherent. After this test run, the corrected questionnaire was distributed to the residents. In the second phase of the study, Observations of waste disposal patterns of the residents and the local authority were carried out and pictures of the disposal patterns were also taken. Interviews of key informants like the health director for the city of Gweru, Environmental Management Agency officer and senior citizens were done and focus discussions were also carried out. Content analysis of the city council, Environmental Management Agency documents and newspaper articles was also done. The objective was to find out the waste disposal practices of all the major stakeholders.

\section{Sampling}

The study employed a two stage sampling procedure for data collection. Purposive sampling was employed in the selection of the wards to be focused on and cluster sampling was used to identify respondents for the questionnaire survey. Gweru has a total of 18 wards. Of these 12 were purposively selected since they occur in areas that are described as high density areas. These high density areas seemed to be the epicenter of illegal dumping of hygienic absorbent materials, hence their selection as the study area. Cluster sampling was then employed to zero in on the specific households that were included in this study. This sampling method was favored as a way of cutting costs while managing to capture a representative sample of the population. Judgmental sampling was used to select key informant interviewees and documents that were analysed. This sampling technique enabled the researcher to pin point respondents and documents that were relevant to the purpose of the study.

In this research the total size of the group was drawn using the number of households in the area under study. This decision was motivated by the fact that the households are the major sources of the waste under review. The population was drawn from the high density residential areas of Senga/Nehosho (ward 5), Mtapa/Mambo/ (ward 6, 7 and 8) and Mkoba (wards 9-17). The total number of households in these areas was 31,562. According to the Raosoft web based sample calculator, if a population is 31,562 the sample becomes 380 . These samples were drawn proportionally basing on the latest census figures of 2012. The cluster sampling procedure was as follows. Each high density area was considered as a cluster. Each of these suburbs was divided into sections e.g. Senga area 1, Mkoba village 1 and Ascot infill sections. Sections were therefore selected randomly but proportionally, depending on the number of 
sections each area has. From the randomly selected section streets, clusters were randomly selected. The survey was then done in the selected street clusters targeting the households there.

The areas under study had the highest densities of population in the city. The households had an average membership of about four people per household. Given the differences in the number of households, a proportional sample from each area was drawn to ensure equal representation in the sample.

\section{Research Instruments}

Data was obtained using observations, interviews, questionnaires, literature reviews and focus group discussions. The questionnaire was used to collect information from residents in the study areas. The semi-structured questionnaire primarily sought to assess how the residents were disposing AHPs. The first category of questions explored personal information about the respondents. The second category explored the disposal methods of hygienic absorbent products and the reasons for the disposal methods cited by the respondents (question 4-19). The last set of questions explored the possible solutions to the problem of illegally dumping hygienic absorbent products and who the residents blamed for the illegal dumps. Following the questionnaire survey, the researcher visited all the areas under study for the sole aim of making observations concerning the disposal patterns of AHPs. The researchers also sought to observe the waste collection practices of the city council in these neighborhoods. Pictures were taken to record the waste practices in the neighborhoods and at McFadden city council dump site (Photos attached at the end of this work).

The observation trips were also backed by thorough document analysis of council, Environmental Management Agency and newspaper articles. Some of the documents that were analysed include the Environmental Management Act, Urban Councils Act and Gweru Urban Constituency Profile. Literature was reviewed for the purpose of assessing the findings of other researchers in this area and to discover a niche that had not yet been explored by previous researches as well as consistencies and inconsistencies in previous research. Focus group discussions comprising an average of 4 people were conducted. The unstructured group discussions sought to assess the disposal patterns of both disposable diapers and sanitary pads. They also sought to find out the reasons behind the observed patterns. Privacy assurances were given to the participants, to ensure that they were confident that all the information they gave would be used for academic purposes only. A semi-structured interview guide was prepared with specific questions that were derived from the objectives of the study. The researcher interviewed key respondents who were meant to supply highly technical information which was not readily available. The interviews with the key respondents were semi-structured in nature. The interviews helped the researcher to cross-check the information supplied by other stakeholders and to understand the scope of the waste disposal problem at hand. Three key informants were interviewed. These were the Quality Control Manager at EMA, the Cleaning Superintendent with the city's health department and some Senior citizens.

\section{Reliability and Validity of the Research Instrument}

A pre-survey was conducted in the study areas to ascertain the clarity of the questions and consistency of the responses. This exercise unearthed some anomalies concerned with the usage of English language. Some of the respondents were apparently unfamiliar with some terms like disposable diapers, washable diapers, sanitary pad, dispose and mensuration. As a way of enhancing the reliability of the questionnaire, these terms were explained parenthetically in a vernacular. There is no doubt that these parenthesis enhanced the respondents' comprehension of the terms at hand. Reliability of research findings was also ensured by use of more than one method of data collection. Thus questionnaires, observations, focus group discussions and interviews ensured reliability of the research findings. Furthermore findings were compared with empirical studies by other researchers. Last but not least, the researcher guaranteed confidentiality by promising the participants that the information they supplied would be used purely for academic purposes hence they were motivated to give uncompromised information without any reservations.

Some considerations were put into ensuring that these instruments addressed the demands of the research objectives. Research experts were enlisted to verify whether the instruments of choice were truly on course to realize the objectives of the study. Similar studies were also perused as a way of

\section{East African Journal of Education and Social Sciences (EAJESS) 1(2)54-64}


ascertaining whether there were consistencies in the instruments that were used and the instruments that were selected for this study. The wide consultations and the earnest perusal of related studies inspired the crafting of a pilot test that was done with about 30 questionnaires. This pilot test was meant to ascertain the feasibility of the research, check clarity of questions, to address ambiguity and also to verify the adequacy of the instrument in addressing the research problem.

\section{Findings and Discussion}

This section was arranged into two parts, one section for results and the other for the discussion. Material is covered under the following headings: (1) amount of AHPs being disposed (2) fate of AHPs in the residential areas (3) fate of AHPs at the municipal dump (4) why residents dispose AHPs the way they do etc. (5) Remedial actions to fight the unsustainable disposal of AHPs. These aspects are the foundation upon which this study aimed to develop a home grown framework to solve the problem of unsustainable disposal of AHPs.

\section{Amount of AHPs being disposed}

The research established that $60.7 \%$ of the respondents used the disposable diaper, $24.60 \%$ used both and $12.90 \%$ used the washable diaper. The city council is facing the daunting task of collecting an average of about 1329 diapers per year per child. These staggering numbers suggest that the city council should come up with a robust strategic plan to deal with this type of waste. The city council has to deal with an average of 5 disposable sanitary pads per every menstruating woman per month. The huge volumes of AHPs discussed here are consistent with (Vidal, 2019)'s report that the municipalities in South Africa are overwhelmed with 4 billion diapers every year. This also concurs with Green Building Council (2018)'s estimate that AHPs are the $4^{\text {th }}$ largest recyclable waste at landfills worldwide.

\section{Fate of AHPs at the Municipal Dump}

At McFadden municipal dump, the researcher observed that disposable diapers seem to enjoy the dump's permanent residence status. This is so because burying or burning them does not provide a permanent solution. When they are burnt, the disposable diapers suffer only superficial damage. When buried in the ground, they take about 500 years to decompose (Rahat, Sarkar, Rafie and Hossain 2014 ). The few sanitary pads that find their way to McFadden facility suffer the same fate as the disposable diapers since they are no separation facilities at the landfill.

\section{Fate of AHPs in the Residential Areas Disposable diapers}

Residents disposed disposable diapers in three main ways. Firstly, some deposited diapers in plastic bags that would be collected by the municipal authority. It was observed that this was the least preferred disposal method. Secondly, some simply dumped them in open spaces. The third method of disposal was noted to be a new phenomenon that has not been documented before, at least according to the researcher's knowledge. This is a sporadic way of disposal, for which the researcher has coined the name Jay-dumping. This new pattern was a result of people who preferred dumping diapers on discreet personalized dumps scattered a little further away from the residents and communal dumps that usually occur close to the households. This new trend has the capacity to instigate new research to further explore the new phenomenon. The jay dumps were observed to be far smaller than the communal dumps. On close inspection it was quite evident that in most cases these dumps belonged to one person. This conclusion was arrived at after noticing that more often than not the diapers that were disposed here would be of mostly one type. Many of the jay-dumped disposable diapers fall victim to veld fires. These fires do very little to destroy the diaper.

\section{Sanitary pads}

In the questionnaire, a majority (61.6\%) indicated that they burnt their sanitary wear. Some preferred burning, others disposed them in bins together with other forms of waste. Another section of women preferred flushing them down the toilet and a few said they dumped them at illegal dumps since it was a taboo to discard pads openly. Some women felt that dumping the pads far away from the home at discreet locations was a better option as opposed to putting them in bins where they could be seen by other users. These disposal trends were the same everywhere except in Senga. Senga's Midlands State University student population generally felt it more convenient to wrap the used pad and throw it in the bin or at an illegal dump site.

\section{Why Do Residence Dispose AHPs the Way They Do? \\ It was found out that $50 \%$ of the respondents indicated that they burnt used disposable diapers because of the city council's ineptitude to manage}


AHPs. Furthermore $34 \%$ of the respondents indicated that they did not dispose used diapers in the bin, mainly because of poor collection or bins filling up quickly, while just $16 \%$ cited cultural reasons to explain the way they disposed disposable diapers. Concerning sanitary pads, it was found out that $67.1 \%$ of the respondents blamed the city fathers (the municipality authorities) for the way they disposed the pads. A further 22\% however cited cultural reasons to explain the way they disposed sanitary pads. The difference between the influence of culture on the disposal of diapers and the disposal of pads can be interpreted to mean that culture has more to say about the disposal of sanitary pads than it does about disposal of diapers.

In one suburb, it was sadly observed that by 14:00 hours the refuse truck had not yet made its rounds. Chances are that the uncollected waste would end up at a dump somewhere. On waste collection days it was noticed that diaper bags were quite varied. This observation implies that the collection of used diapers was either not systematized or the system had collapsed. In another suburb, the black bin liners, which residents use to dispose waste, were observed to be far less than the number of houses. Another observation that was made was that the number of bins along the main Nehosho road was far greater than the number of bins along the smaller roads. This confirmed the allegation by some residents that the refuse trucks are more efficient in collecting bins along this road than along the smaller feeder roads. The inconsistent bin collections and lack of bins could be the most important explanation for the occurrence of many illegal dumps in the areas under study.

\section{Remedial Actions to Fight the Unsustainable Disposal of AHPs}

To remedy the challenges posed by illegal dumping of disposable diapers and sanitary wear, three remedial actions topped the list of proposals from the questionnaire survey. It was found out that 35\% felt that the city fathers should improve on waste collection and a further 35\% suggested that educational campaigns could help the situation and some suggested provision of more bins. In a wide ranging interview with a city council officer, a few overarching remedies involving all manner of waste were proposed. The officer recommended the hiring of more workers and the acquisition of more compactors. Most of the remedial actions that were recommended put the city council right at the center of all possible interventions that can be made.

\section{Institutional Shortcomings that Hinder the Waste Management of AHPs}

A number of institutional shortcomings were noted. Firstly the study established that the city does not have a department that monitors consumer patterns and their waste disposal patterns. Secondly leadership fatigue was observed. For instance, one EMA official shied away from putting forward any recommendation on how to deal with the problem of diapers because of his view that no solution could really work until there was a positive movement on the political and economic front. He frankly admitted that currently EMA has no plans to deal with the problem of disposable diapers because they lacked the institutional capacity to act against diapers. He also felt that the city council lacked the institutional capacity to deal with the illegal dumping of diapers as well. In his view, a poor economy and lack of political will were the main factors militating against EMA's wish to carry out its mandate as stipulated by the law.

\section{Discussion}

Here discussions are presented in relation to findings of the study.

\section{Amount of AHPs Being Disposed}

According to Green Building Council (2018), AHPs are the fourth largest contributor by volume to landfill space the world over. In the developing world, they are largely disposed improperly disposed both in the residential areas and at the municipal dump, thus pausing a big threat to the environment. This study therefore set out to find a solution that would account for each and every diaper that is used in Gweru's municipal jurisdiction, with a negligible error margin. Such a model should wholesomely address the problems associated with AHPs both in the residential areas and the city dump.

\section{Fate of AHPs in the Residential Areas and $t$ the Municipal Dump}

Study results indicated that AHPs were being improperly disposed in most high density areas due to the shortcomings of the city council. However no real time figures for the amounts of diapers being disposed were available, for the areas under study. Pellow (2004)'s assertion that there is a lot of unfairness that influences the existence of dumps in certain areas was collaborated by this study's

\section{East African Journal of Education and Social Sciences (EAJESS) 1(2)54-64}


findings. It seems odd that waste in high density areas is collected once per week while waste in the sparsely populated low density suburbs is also collected once a week. On the same note, Mangizvo (2014) echoes the point that the inefficiencies of the city refuse collection system leaves the residents with no choice at all but to dump disposable diapers at illegal communal dump sites.

There was one unique observation that was not found in any of the literature that was reviewed. The disposal of AHPs in a scattered fashion was a departure from the communal dumping of AHPs, to a more personalized way of dumping AHPs at discreet locations further away from the residences and the communal dumps. The researcher coined the name jay-dumping to describe this supposedly new phenomenon. It was observed that the Jaydumpers for some strange reason decided to avoid the communal dumps that are located close to the households, opting to dump their waste a little distance away from the households. These dumps were suspected to be personal because the used diapers were in most cases of the same brand. It was also interesting to note that the diapers at these Jay-dumps were not as multi-generational as those on the usual communal dumps, suggesting that the diapers at the Jay-dumps probably belonged to one child. These Jay-dumps were also uniquely much smaller in size compared to the communal dumps. The study also observed variations in the way residents dispose AHPs in different areas. These variations inspired this study to envision a waste management solution that takes into account the unique variations of all the areas, so that financial and material resources can be deployed accordingly. This position was consistent with Hettiarachchi (2014)'s assertion that there is nothing like a one size fits all waste management solution, hence he proposed that waste management systems should be tailor made to suit the unique variations in the society.

The study noted differences in the ways disposable diapers and pads are disposed. Menstrual pads were rarely seen at a dump in the residential areas or at the municipal dump due to myths and taboos concerning the handling of menstrual blood. However, in Senga and outlying areas, sanitary pads could be seen dumped willy-nilly. Here Midlands State University students seem not to worry much about the myths and taboos, hence they had the guts to throw away used pads without even giving it a thought. They blamed the way they disposed sanitary pads on the inefficiencies of the city council.

At the municipal dump, the AHPs continue to endanger the environment. Their inability to readily burn or decompose means that they are a difficult type of waste to deal with. In fact research has shown that they can take as much as 500 years to decompose (Rahat,(2014 ). The Manica Post (2016) reports that these municipal dumps do not offer conditions that are ideal for diaper decomposition, hence there is a great need to invest in sustainable ways of dealing with this waste at the municipal dump.

The summary of this discussion is that there are no real time statistics about the amount of AHPs that are being disposed by the residents. Some seem to agree that they are many but no specific figure is given. The big question that is addressed by this study is, is it feasible to deal with a problem that has not been measured?

\section{Remedial Actions to Fight the Unsustainable Disposal of AHPs}

The solutions proffered by respondents in this study were not influenced by real time data. The results showed that the changing times have not been met by a reciprocal change in the waste management strategies. The study also showed that the city lacked waste management solutions for specific types of waste, as all waste was treated the same. Lastly it must be highlighted that most of the waste management solutions that were proffered in this study limited the waste management challenges to the residential areas and ignored the fact that AHPs dumped at the city's dump site can be equally dangerous to the environment and people as well.

Some of the solutions that were proposed by the residents in the study include the following; improving waste collection by the city council, running educational campaigns, increasing the number of city cleaners, increasing cleaning equipment and running clean up campaigns. These solutions seem to address all manner of waste. They also seemed to be very different from what other researchers proposed in similar studies. This may be taken to mean that Gweru is a unique town which rightfully deserves a unique waste management model to deal with AHPs. In one study, Wilson, Whiteman, and Tormin (2001) asserted that 'if you don't measure it you can't manage it.' They also 
underscored the point that if knowledge is power then a city without knowledge of its solid waste system may lack the power to make positive changes.

It's sad to note that recommendations by the respondents and those from previous studies did not in any way underscore the importance of real time data capture. The respondents in this study missed the concept that the success of waste management is underpinned by the participation of all stake holders. In a previous study, Owen (2017) says that given the complexity of diaper problems, possible solutions should involve all stakeholders, from households, communities, civil society organizations, government departments and the industry. The involvement of so many players in waste management entails that there can never be a one size fits all solution since the roles of these entities differs from country to country. These differences should be measured and captured as part of real time data which should be used to determine the nature of the waste management model that has to be employed to win the battle against illegal disposal of AHPs. The Standard (2011) advanced the point that solutions to problems concerning the disposal of AHPs lie in the sorting of garbage at house hold level. Another unique proposition came from Wilson (2001) who talks about having a sound financial system as a prerequisite to sound waste management.

While all these recommendations sound noble on the face value, they seem to be lacking one ingredient. The ingredient that seems to be lacking in good solutions that were proposed by previous researchers is real time data capture. Real time data can be captured by online systems like GPS and mobile phone applications. Previous studies ignored this aspect of data. This gap inspired this study to envision a model built upon data capture as the basis upon which the waste management should be run. There is therefore a great need that the local authority gathers a lot of real time data about AHPs in order for them to be able to deal with this waste effectively.

\section{Institutional Shortcomings that Hinder the Waste Management of AHPs}

The study's results showed serious institutional weaknesses. It was this study's view that these weaknesses were a result of a fragmented system with entities that are given to blaming each other as opposed to the entities viewing themselves as part of an integrated waste management system. Due to these institutional challenges, this study envisions a system that brings the major entities e.g. politics, EMA, residents, city council into the system as opposed to them being spectators of the system.

\section{The Proposed Real Time Data Waste Management System}

This study proposes a waste management system that is not cast in stone. Its flexibility is a result of the fact that it is designed to respond to real time data. The reaction of the system in response to the changes in real time data can be likened to the way a human body perspires when temperature rises and how it develops goose bumps when it becomes cold. The action of the waste management system will likewise be a direct response to the data inputted into the systems, hence the name Real Time Data Waste Management System. The key tenets of the proposed waste management system are: a data nerve center; households; a mobile application; GIS monitored, personal and communal bins with volumetric sensors; GIS monitored compactors; power generation plant; recycling plant, a landfill and an independent financial system. The nucleus of this system is the data nerve center. This nerve center gets information from the GIS connected volumetric sensors, located in both the personal bins and the communal bins; the resident's mobile gadgets and mere observations. It is this data that then detects how the city's waste disposal resources are deployed. For instance, if a volumetric sensor indicates that a bin is full, the authorities should then deploy the most cost effective and environmentally sound remedy. The full package of remedies include: waste reduction, waste reuse, waste recycling, power generation, incineration and landfilling. This system is designed to be self-sustaining i.e. it should finance itself, autonomously running its funds apart from the city's fiscal structures.

\section{Conclusions and Recommendations}

Conclusions are given based on the findings of the study. Thereafter corresponding recommendations are presented.

\section{Conclusions of the Study}

The One conclusion that can be drawn from this study is that the city council is making very little effort to understand the character of the problem they are up against. The council has a superficial understanding of the problem at hand. There are 
very few statistics concerning AHPs. For instance, the number of illegal dumps, the number of AHPs they have to deal with in any given week, month or year; the types of AHPs that are on the market, etc. It was this lack of data that inspired this study to endeavor to craft the self-adjusting waste management model that can be applied by the Gweru city council or any local authority. This study explored the potential of devising an AHP waste management model that is not cast in stone, but one that meticulously responds to the dynamic socio-political and economic situation. In other words, the city would do well with a model which can self-adjust in response to the situation obtaining on the ground. The key to such a home grown solution can only be realized if all waste management solutions are anchored on a robust system of gathering real time data about AHPs.

\section{Recommendations of the Study}

This study recommends a home grown waste management framework with the capacity to selfadjust in response to real time data. From the start of the study it was observed that the use of AHPs was very dynamic as it responded to the sociopolitical and economic situation in the country. During times of economic prosperity, there was popular usage of AHPs and at other times the economy would fall so much that the use of these products would fall drastically. Given these varied scenarios, this study recommends a waste management model that can adjust itself in accordance with the fluctuations that occur on the socio-political and economic front. This system should also be able to adjust to the changes that occur in the various entities e.g. politics and EMA. These adjustments should be automatic since these entities will be inbuilt, in the waste management model. In other words this study recommended that financial and material resources be deployed in measures that are commensurate with the situation obtaining on the ground. The situation i.e. the real time data can be gathered by way of various gadgets and processes. Some of these gadgets and internet applications include volumetric sensors, GPS, smart phones etc.

\section{Reference}

Adogu, P. O. (2015). Assessment of Waste Management Practices among Residents of Owerri Municipal Imo State Nigeria. Journal of Environmental Protection, 6, 446-456.
Retrieved

from

http://dx.doi.org/10.4236/jep.2015.65043

Bhada-Tata, P., \& Hoornweg, D. (2012, March). WHAT A WASTE A Global Review of Solid Waste Management. Washington, DC, USA: Urban development \& local government unit world bank. Retrieved from http://www.worldbank.org/urbanA

Diaz, L. (2011). Solid Waste Management in Developing Countries: Status, Perspectives and Capacity Building. Intergovernmental Preparatory Meeting for CSD-19. New York: United Nations Headquarters.

Elledge, M., Muralidharan, A., Woodward, K. P., Ravndal, K., Siddiqui, M., \& Toolaram, A. (2018). Mentrual hygiene management and waste disposal in low and middle income countries . International journal of environmental research and public health. doi:10.3390/ijerph15112562

Green Building Council. (2018, June 12). Tackling the environmental impact of disposable nappies. Johannesburg, South Africa.

Hettiarachchi, H. (2014). Open dumps to Nexus approach:Historical evolution of waste management. Sustainability in the waterenergy-food nexus an environmental resources perspectives. Bonn, Germany: United Nations University.

Kamba, M. (2018, May 24). Disposable diapers environmental menace. The Patriot.

Macmillan Education. (2007). Macmillan English Dictionary (2nd ed.). (M. Rundell, Ed.) Oxford: Macmillan Publishers Limited.

Mafume, P., Zendera, N., Mutetwa, W. M., \& Musimbo, N. (2016, December). Challenges of solid waste management in Zimbabwe: a case study of Sakubva high density suburb. Journal of environment and waste management, Vol. 3(2), 142-155. Retrieved from htt:p//www.premierpublishers.org, 
Mangizvo, R. V. (2014, April -June ). The environmental health implications of the use and disposal of disposable diapers in Senga/Nehosho suburb in Gweru city Zimbabwe. Global Journal of of Biology,Agriculture and Health Sciences, Vol.3(2). Retrieved from http://www.gifre.org

Mathe, M. P. (2015, June). Management of Municipal Solid Waste in Gwanda Town. International Journal of Scientific \& Engineering Research, Volume 6(Issue 6), 1555-1567. Retrieved from http://www.ijser.org

Matiashe, F. (2018, March 30). Diaper disposal a headache for stake holders. NewsDay.

Memon, M. (2010). Integrated solid waste management based on the 3R approach. Journal of Material Cycles and Waste Management - April 2010. doi:DOI: 10.1007/s10163-009-0274-0

Nyanzou, P., \& Jerie, S. (2014). Solid Waste Management Practices in High Density Surbubs of Zimbabwe: A Focus on Budiriro,Harare. The Dyke, 8.3. Retrieved August 14, 2015

Owen, P. (2017, September 18). Diapers- A growing threat to African rivers. End Water Poverty.

Pellow, D. (2004). The Politics of Illegal Dumping: An Environmental Justice Framework. Qualitative Sociology, 27(4).

Rahat, S. H. (2014). Prospects of diaper disposal and its environmental impacts on populated urban area like Dhaka City. 2ndInternational Conference on Advances in Civil Engineering. Chittagong, Bangladesh.

Tembo, E., \& Chazireni, E. (2016, October ). The negative environmental impact of disposable diapers: The case of Mberengwa District, Zimbabwe. International journal of healthcare sciences, Vol. 4( Issue 2), pp:
(2158-2161). Retrieved from http:// www.researchpublish.com

The Manica Post. (2016, December 02). Environmental friendly diaper disposal options. The Manica Post. Retrieved from https://www.manicapost.co.zw/environme ntal-friendly-diaper-disposal-options/

The Standard. (2011, December 17). Concern over disposal of sanitary waste. The Standard.

Vidal, J. (2019, April 19). Baby diapers are hiding some dirty, dangerous secrets. Retrieved from Huffpost: https://www.huffpost.com/entry/babydiapers-oceanplastic_n_5cb77ea7e4b096f7d2db869b

Wambui, K., Muchiri, J., \& Makindi, S. (2015, October ). Soiled diapers disposal practices among caregivers in poor and middle income urban settings. International journal of scientific and research publications, Volume 5( Issue 10). Retrieved from http://www.ijsrp.org

Whiteman, A., Smith, P., \& Wilson, D. (n.d.). Waste management: an indicator of urban governance. Proceedings of UN-Habitat Global Conference on Urban Development. Retrieved 07 27, 2011, from http://www.davidcwilson.com/Waste_Man agement_An_Indicator_of_Urban_Governa nce.pdf

Wilson, D., Whiteman, A., \& Tormin, A. (2001). Strategic planning guide for municipal solid waste management. For the collaborative working group on solid waste management in low and middle income. Washington D.C.: World Bank. Retrieved from http:// www.worldbank.org/urban/solid_wm/erm/ start_up.pdf

Zimbabwe National Statistics Agency. (2012). Provincial Report Midlands. Harare: Zimbabwe National Statistics Agency. 


\section{PHOTOS}

Photo 1: Gweru City Municipal Dump

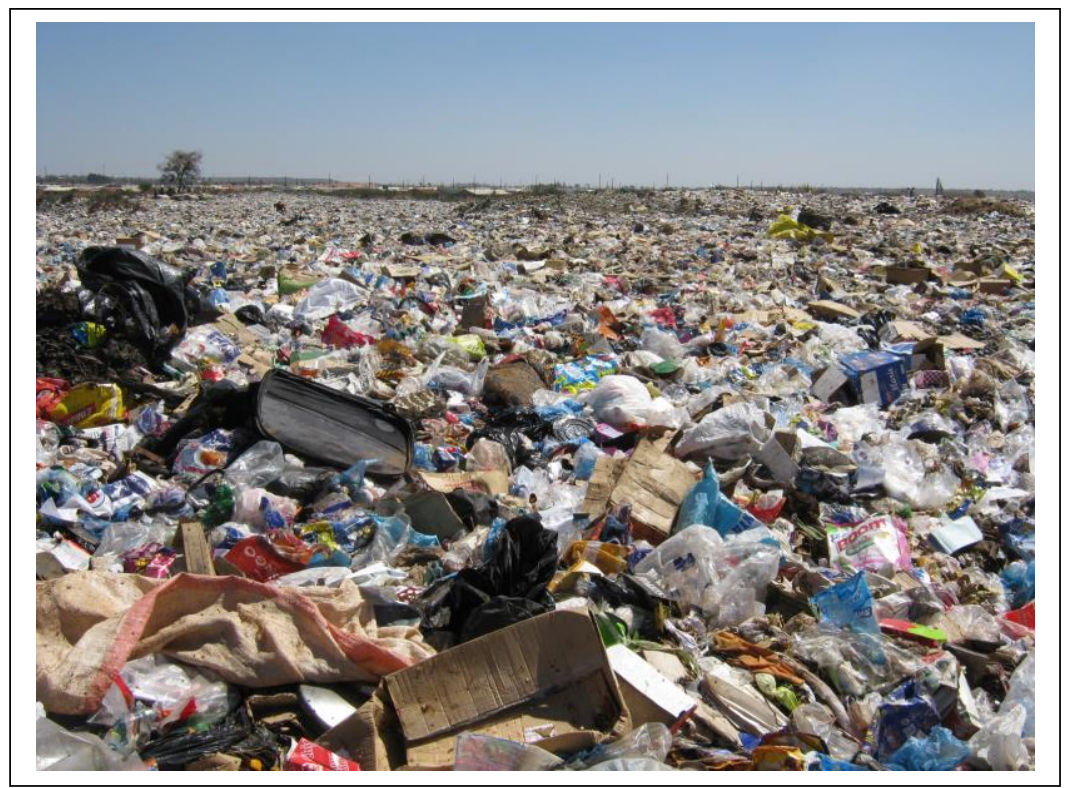

Photo 2: Diapers disposed at a communal dump in the a residential areas

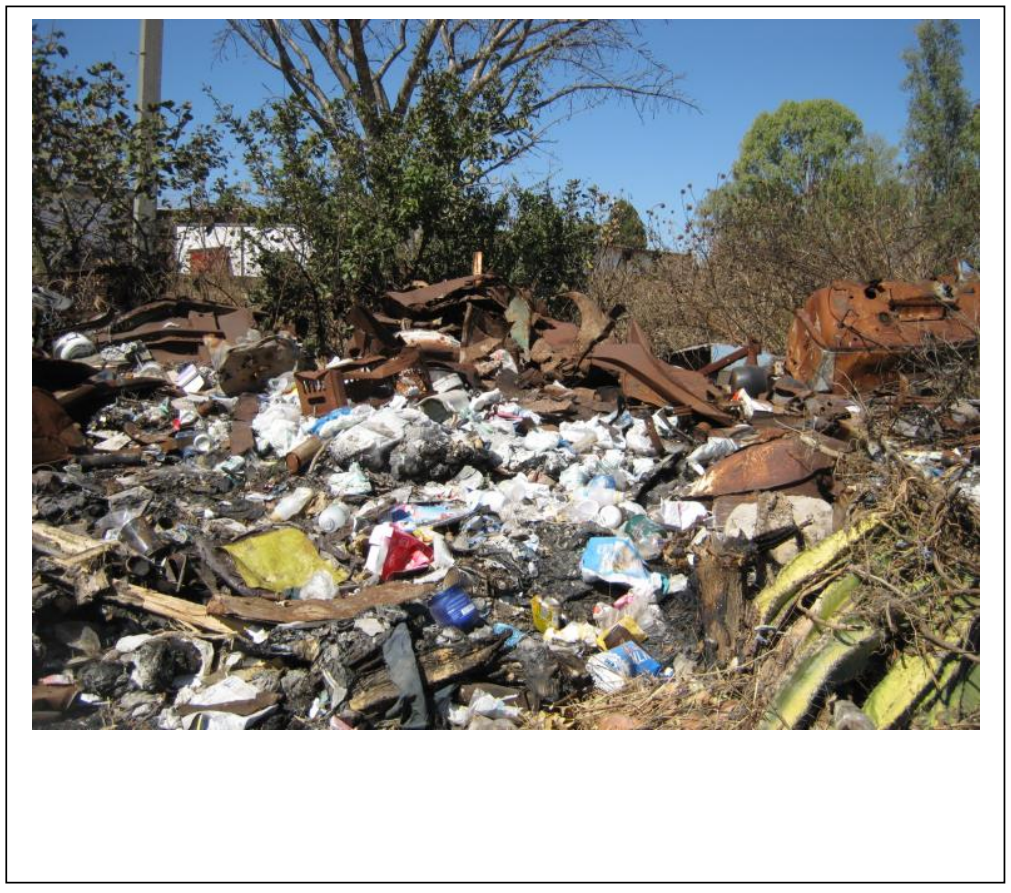

